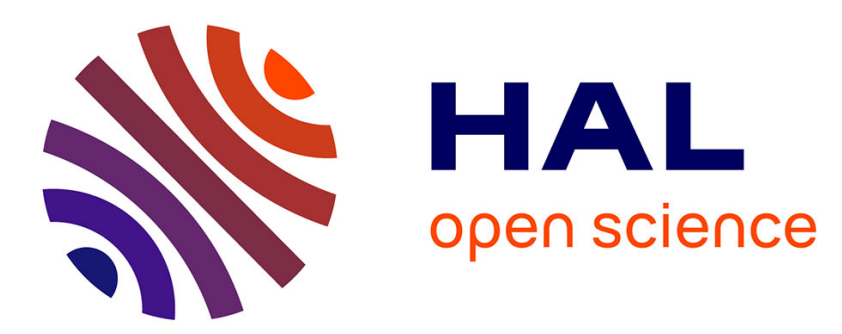

\title{
A fault detection method for an automatic detection of spawning in oysters
}

Hafiz Ahmed, Rosane Ushirobira, Denis Efimov, Damien Tran, Mohamedou Sow, Laura Payton, Jean-Charles Massabuau

\section{- To cite this version:}

Hafiz Ahmed, Rosane Ushirobira, Denis Efimov, Damien Tran, Mohamedou Sow, et al.. A fault detection method for an automatic detection of spawning in oysters. IEEE Transactions on Control Systems Technology, 2016, 24 (3), pp.1140-1147. 10.1109/TCST.2015.2472999 . hal-01185118

\author{
HAL Id: hal-01185118 \\ https://hal.inria.fr/hal-01185118
}

Submitted on 9 Oct 2015

HAL is a multi-disciplinary open access archive for the deposit and dissemination of scientific research documents, whether they are published or not. The documents may come from teaching and research institutions in France or abroad, or from public or private research centers.
L'archive ouverte pluridisciplinaire HAL, est destinée au dépôt et à la diffusion de documents scientifiques de niveau recherche, publiés ou non, émanant des établissements d'enseignement et de recherche français ou étrangers, des laboratoires publics ou privés. 


\title{
A fault detection method for an automatic detection of spawning in oysters
}

\author{
Hafiz Ahmed, Rosane Ushirobira, Denis Efimov, Damien Tran, Mohamedou Sow, Laura Payton, Jean-Charles \\ Massabuau
}

\begin{abstract}
Using measurements of valve activity (i.e. the distance between the two valves) in populations of bivalves under natural environmental condition (16 oysters in the Bay of Arcachon, France, in 2007, 2013 and 2014), an algorithm for an automatic detection of the spawning period of oysters is proposed in this paper. Spawning observations are important in aquaculture and biological studies, and until now, such a detection is done through visual analysis by an expert. The algorithm is based on the fault detection approach and it works through the estimation of velocity of valve movement activity, that can be obtained by calculating the time derivative of the valve distance. A summarized description of the methods used for the derivative estimation is provided, followed by the associated signal processing and decision making algorithm to determine spawning from the velocity signal. A protection from false spawning detection is also considered by analyzing the simultaneity in spawning. Through this study, it is shown that spawning in a population of oysters living in their natural habitat (i.e. in the sea) can be automatically detected without any human expertise saving time and resources. The fault detection method presented in the paper can also be used to detect complex oscillatory behavior which is of interest to control engineering community.
\end{abstract}

Index Terms-Fault Detection, Spawning, filtering.

\section{INTRODUCTION}

Global awareness regarding our aquatic environment increases daily. This consciousness combined with the pressure from the general public, scientists and environmental protectionists and various other reasons lead to more and more strict rules and regulations for the protection of environment. In order to better protect the aquatic environment, a detailed analysis of the behavior of marine animals in their natural habitat could be essential. From this necessity, various monitoring approaches have already been proposed to observe the behavior of marines organisms. For example, Mussel Watch [1], which is considered the first step towards a

Hafiz Ahmed, Rosane Ushirobira and Denis Efimov are with the NonA team, Inria, Parc Scientifique de la Haute Borne, 40 avenue Halley, 59650 Villeneuve d'Ascq, France, \{hafiz.ahmed, rosane.ushirobira, denis.efimov@inria.fr\}. Damien Tran, Mohamedou Sow, Laura Payton and JeanCharles Massabuau are with Université Bordeaux 1, Centre National de la Recherche Scientifique (CNRS), Unité Mixte de Recherche (UMR) 5805 Environnement et Paléoenvironnement Océanique et Continental (EPOC), Arcachon, France and the EA team at UMR 5805 EPOC-OASU, Bordeaux, France, \{d.tran, m.sow, 1.payton, jc.massabuau@epoc.u-bordeaux1.fr\}. D. Efimov is also with CRIStAL UMR 9189, Ecole Centrale de Lille, Avenue Paul Langevin, 59651 Villeneuve d'Ascq, France and with Department of Control Systems and Informatics, University ITMO, 49 avenue Kronverkskiy, 197101 Saint Petersburg, Russia. This work was partially supported by the Government of Russian Federation (Grant 074-U01) and the Ministry of Education and Science of Russian Federation (Project 14.Z50.31.0031).

H. Ahmed is partially supported by the regional council of Nord-Pas de Calais, France global marine monitoring. These monitoring methods made available a lot of data collected from the field regarding marine animals. Specifically, it opened up a new horizon for a more detailed biological and mathematical analysis of marine animals behavior that was not possible before.

Oysters and mussels are widespread throughout the world and represent a key element in the ecology and economy of coastal ecosystems [2]. Large scale monitoring of bivalves, like oysters and mussels, has been taking place for quite a long time [3]. One such project is "MolluSCAN eye", a remarkable solution that records the valve activity of bivalves in various geographical location in Europe, Arctic and Tropics ${ }^{1}$. The data obtained from this project make possible the analysis of behavior of various bivalves from field measurements. These dataset lead to the successful study on various aspects of oysters behavior like the existence of rhythms [4], [5], [6], growth rates [7], behavioral response to harmful algae exposure [8], [9], growth rate recording [10], ecological monitoring [11] and so on.

In this work, we are interested in a particular behavior of oysters, i.e. their behavior during reproduction also known as spawning. Spawning is characterized by rapid and rhythmic contraction and relaxation of the valve to expel eggs in the water. Spawning observation is important in domains like aquaculture, ecology, etc. In [11], it was shown that the deviation of valve activity from normal behavior (i.e. slow and non rhythmic contraction and relaxation of valve) can be used as an automatic tool to suspect pollution in surrounding water. Spawning behavior is a deviation from normal behavior but not caused by pollution, so it is necessary to distinguish a spawning behavior from any other behavior. The motivation of the current paper comes from this necessity. The basis of our work is the valve activity dataset of the MolluSCAN eye project recorded in the Bay of Arcachon, France in 2007, 2013 and 2014

Our goal in this study is to develop an algorithm that can automatically detect spawning in oysters using the valves movements data (i.e. the distance between the two valves of the oyster). Data were collected using high frequency noninvasive (HFNI) valvometry (details can be found in section II). In [12], P. S. Galtsoff did this detection by visual inspection under laboratory conditions. Due to various technical limitations (for example, unavailability of appropriate sensors in 1938), the recording of valve movements were limited in order to measure the data. This type of approach required constant attention, labor and experience to analyze and detect

\footnotetext{
${ }^{1}$ http://molluscan-eye.epoc.u-bordeaux 1. fr/
} 
some spawning behavior, as it occurs once or twice a year. An increasing number of online measurements for different populations of oysters makes this manual detection approach unpractical due to a big amount of data to be permanently analyzed visually by an expert. Therefore a solution is an automatic detection of the spawning that can save a lot of time and resources. In this perspective, spawning can be then considered as a deviated behavior or as a fault [13], [14], [15]. This paper proposes the algorithm to detect this phenomenon.

The novelty and the relevance of this paper lie on a new application of the fault detection theory for the analysis of bivalve physiology and for an automatic recognition of spawning. In this case, spawning is considered as a deviation from the normal behavior, then it can be interpreted as a "fault" of the system, which has to be detected. Introducing several differentiation algorithms as software sensors of valve movement velocity, the analytical redundancy approach is applied for this biological system. In general, in biological or medical applications, it is rather difficult to apply an engineering approach due to lack of measured information and mathematical models. However, in the considered application the valve distance measurements are available with a required frequency that makes possible the use of control engineering tools in the new setting. In addition, the authors hope that, by itself, the reported application of detection of complex oscillatory behavior is of interest for the control engineering community.

The outline of the paper is as follows: a brief description of the measurement scheme and experiments is given in Section II (a more detailed information can be found in [16], [17], [18]). The processing of obtained data through Section II is discussed in Section III. Spawning behavior of oysters are summarized in section IV while the detection of spawning is presented in section V. Section VI contains the results and the discussion. The conclusion of this work can be found in Section VII.

\section{Measurement System Description}

The monitoring site is situated in the Bay of Arcachon, France, at the Eyrac pier (Latitude: $44^{\circ} 40 \mathrm{~N}$, Longitude: $1^{\circ}$ $10 \mathrm{~W})$. Sixteen Pacific oysters, Crassostrea gigas, measuring from $8 \mathrm{~cm}$ to $10 \mathrm{~cm}$ in length were permanently installed on this site. These oysters were all from the same age group (1.5 years old) and came from the same local supplier. They also all grew in the Bay of Arcachon. They were permanently submerged on the sea bottom (at $3 \mathrm{~m}$ to $7 \mathrm{~m}$ deep in the water, depending on the tide activity).

The basic principles of the measurement process have been first described in [18]. It was further modified later on in [19]. A significant advantage of the developed monitoring system at sea is that it is completely autonomous without in situ human interference for at least one full year. Each animal is equipped with two lightweight coils (sensors), $\approx 100 \mathrm{mg}$ each, attached on the edge of each valve. These coils measure $2.5 \times 2.5 \times 2 \mathrm{~mm}$ and were coated with a resin sealing before attaching them on the valves. One of the coils sends a highfrequency sinusoidal signal, that is received by another coil.

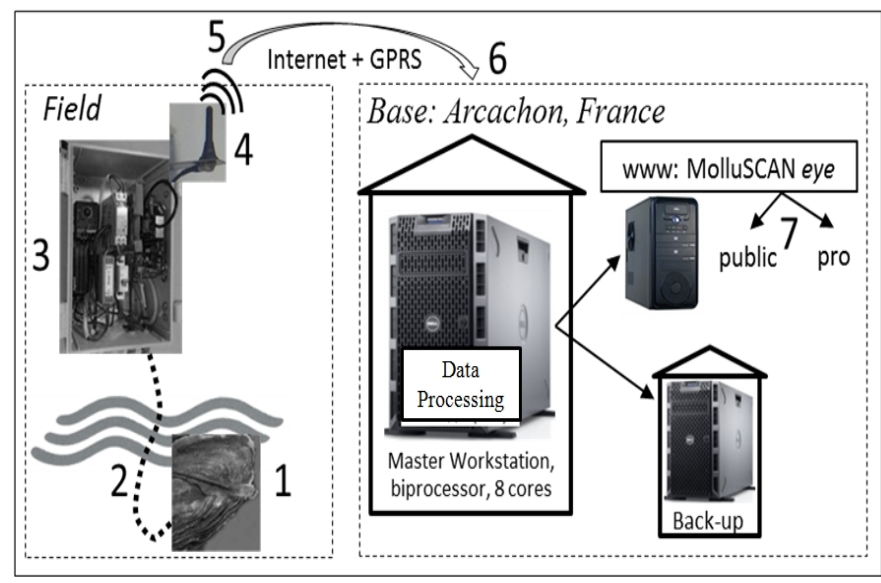

Figure 1. [17] Synoptic representation of the system, from field to laboratory: (1) Oyster equipped with two electrodes and 1st level electronic card in a waterproof case (immersed); (2) electrical connection between the first and the second electronic cards (umbilical); (3) 2nd level electronic card out of water; (4) GPRS antennae (5) GPRS and Internet connection; (6) Marine Station of Arcachon (Master unit) ready for daily update and for feeding internet (Google: MolluSCAN eye).

Measurements are performed every $0.1 \mathrm{sec}$ successively (with the frequency $10 \mathrm{~Hz}$ ) for one of the sixteen animals. This means that the behavior of a particular oyster is measured every $1.6 \mathrm{sec}$. Every day, 54000 triplets (1 distance, 1 stamped time value, 1 animal number) are collected for each oyster. The strength of the electric field produced between the two coils is proportional to the inverse of distance between the point of measurement and the center of the transmitting coil, that leads to the estimation of the distance between coils.

On the shore, a second electronic unit takes care of the data acquisition and transmission. This unit is equipped with a GSM/GPRS modem and uses Linux operating system for driving the first control unit submerged in the water, managing the data storage with a time stamp, accessing the Internet, and transferring the data. The whole process is done by using an original self-developed software module and hardware that run with mobile phone technology. At the end of a working day, the collected data is transmitted to a central workstation server located in the Marine Station at Arcachon, France. The valve activity data are stored in a central database and the public access to this database is available via a website (under some restrictions on the amount of data) ${ }^{2}$. A schematic description of the monitoring system is presented in Fig. 1.

\section{DATA PREPARATION}

After a specified duration of the experiment, the electronic system provides a matrix $\left(P_{i, j}\right)$ of values of opening of valves for each oyster $P_{i, j} \in[0,12 \mathrm{~mm}]$ for $1 \leq i \leq N, 1 \leq j \leq n$ where $n=16$ is the number of oysters in the experiment and $N$ is the number of measured points, $N=54000 \times N_{\text {days }}$ where $N_{\text {days }}>0$ is the number of days of measurement. In our case, the dataset of 2007, 2013 and 2014 collected at the Eyrac pier in the Bay of Arcachon have been used. So, $N_{\text {days }}=365$. For the population, i.e. for 16 oysters, the

\footnotetext{
${ }^{2}$ http://molluscan-eye.epoc.u-bordeaux 1.fr/
} 
measurement system gave us total 315.36 million data points. The size of the oysters increases as time passes by. However, the growth rate is different for individual oysters. This diversity is originated by the difference of shell anatomy between animals. To compensate this variability, we normalized the data between certain bounds. In this work, the normalization was done considering a 6 days window and with a bound $[0,1]$, where 0 represents complete closing of the valve while 1 represents complete opening of the valve. The formula to calculate the normalized value is:

$$
p_{i, j}=\frac{P_{i, j}-\min \left(P_{a, j}\right)}{\max \left(P_{a, j}\right)-\min \left(P_{a, j}\right)}
$$

where $a=i-N_{t}, \cdots, i$ with $N_{t}$ the total number of data points in last 6 days, $P_{i, j}$ is the actual valve distance and $p_{i, j}$ is the normalized valve distance.

For further work, we have considered this normalized/scaled data instead of the original one [11], [20].

\section{SPAWNING OF OYSTERS}

For oysters, the experimental study of spawning dates back to 1938, when American biologist Paul S. Galtsoff published his seminal work on the physiology of reproduction of oysters [12]. Based upon laboratory observation, spawning is a specific/particular type of shell/valve activity of female oysters [21], [22]. In [12], an ostreograph was used to measure the valve activity and that data was later used to study spawning. Under normal environmental conditions shell/valve movements are characterized by long relaxation periods which may vary from a few minutes to hours and are often interrupted by secondary contractions. While during spawning (see Fig. 2 or Fig. 3, oysters $\mathrm{N}^{\circ} 1$ and $\mathrm{N}^{\circ} 3$ ), it can be seen that a series of rapid contractions and relaxations are occurring following one after another with remarkable regularity and continuing for about $30-40$ minutes. Consistency in the amplitude of the relaxation curve, especially during the first half of the reaction and the remarkable rhythmicity of the contractions are the most distinctive features of the sexual reaction of a female. This phenomenon does not occur under any other circumstance. Burst of valve activity can be seen in other cases as well as under the influence of some external excitation (for example pollution or chemical injection) but (1) their frequency is never so regular, (2) will last for shorter period of time and (3) will have longer relaxation period. It was also known that spawning propagates from one to another and eventually over a large fraction of the oyster community [12]. Hence, any rhythmic behavior to be considered as spawning should have certain characteristics. For example:

1) regularity in rhythm and consistency in amplitude;

2) happening for $30-40$ minutes with short relaxation period;

3) simultaneous spawning in the population and so on.

In this work, we considered only this type of spawning that is clearly distinguishable. However, spawning can happen with mild characteristics also. For example, instead of $30-40$ minutes duration, it can last $10-20$ minutes. In this work, we will focus on detecting any spawning behavior with
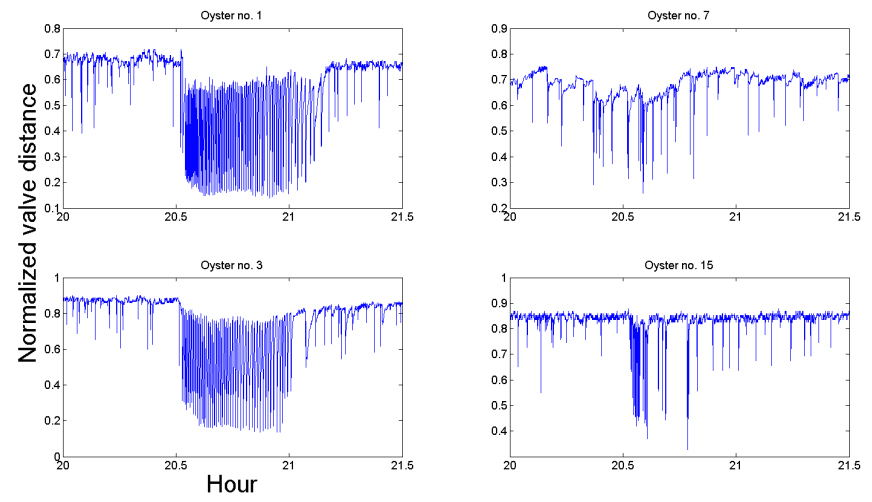

Figure 2. Spawning and non-spawning behavior of oysters

strong characteristics or clearly distinguishable. Therefore, the spawning behavior can be considered as a deviation from normal behavior. In Fault Detection literature [14], [15], this is known as fault (i.e. deviation from normal behavior). So, the detection of this fault is equivalent to the detection of spawning.

In our experiment, we have collected the data of 16 oysters recorded in 2007, 2013 and 2014 respectively. They are denoted as dataset 1,2 and 3 respectively. Two types of oyster data were collected: diploid oysters and triploid oysters. Triploid oysters are genetically modified and have three sets of chromosome while diploid oysters are not genetically modified and have two sets of chromosome. Diploids oysters normally spawn in the summer while triploids cannot spawn because of the genetic modification. For details, the reference [23] can be consulted. Dataset 1 contains only diploid oysters while dataset 2 and 3 contains both diploid and triploid oysters. We had equal number of diploid and triploid oysters i.e. 8 diploids and 8 triploids respectively in dataset 2 and 3 . In our datasets, we also found similar behavior as reported in [12]. In our case, for the first dataset, the oysters happened to spawn on the 15 th of July, 2007. The data of 4 oysters including both spawning and non-spawning oysters can be seen in Fig. 2. A close look on oyster $\mathrm{N}^{\circ} 3$ and 15 , can be seen in Fig. 3, where we can clearly check that oyster $\mathrm{N}^{\circ} 3$ fulfills all the criteria to call its rhythmic behavior as female spawning according to [12] (regular rhythmicity, consistency in the amplitude during rhythmic behavior, happening for about $30--40 \mathrm{~min}$., contraction followed by relaxation or vice-versa with short relaxation period, etc.). However, if we look at oyster $\mathrm{N}^{\circ} 15$, it is evident from its behavior that it is not spawning with very visible characteristics (like $30-40$ minutes duration, very regular contraction and relaxation, etc.) although some rhythmicity can be seen. So, oyster no. 15 is not showing the type of spawning we are interested in this work. Similarly, we can say that oyster $\mathrm{N}^{\circ} 1$ is spawning and $\mathrm{N}^{\circ} 7$ is not spawning in Fig. 2.

\section{Automatic Detection of Spawning}

In the previous Section, details about a spawning behavior were discussed. One point to be noted in this regard is that the detection of spawning is totally manual until now. In one 


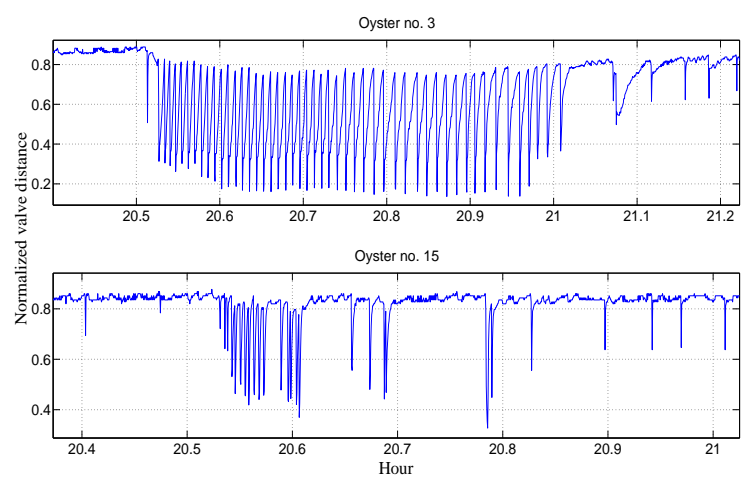

Figure 3. Behavior of oyster $N^{\circ} 3$ and 15 (zoomed)

of our previous works, we have tried to establish a relation between water quality and abnormal valve activity [11]. There, we have showed that the deviation of valve activity from normal behavior, if it occurs in the whole animal group can be used as an indicator for change in water quality. Since the spawning behavior is a total deviation from normal behavior, according to [11], it could also be considered as an indicator for change in water quality. However, in reality this is a totally normal behavior having little to do with the occurrence of poor water quality. By automatic spawning detection, we will be able to differentiate spawning behavior with numerous other abnormal motions. Moreover, it will save time and labor of visually analyzing the data to find the period of spawning. So, automatic detection of spawning can be useful in the above mentioned cases.

A typical pattern of a spawning behavior (see figures 2 and 3 ) is a series of contractions and relaxations of valves. In other words, the velocity of valve movement is fluctuating in a regular rhythmic manner. Since the kinetic energy is related to the velocity, it will also fluctuate very rapidly and regularly. By passing this high frequency kinetic energy like a signal through a specially designed low-pass filter, we can expect to extract some features related to spawning. They can then be used for the detection of spawning.

The main idea of our spawning detection algorithm is first to calculate the velocity of valve movement. Velocity is nothing but the time derivative of the measured distance. Once we estimate the velocity, this information can be used to calculate the energy (square of velocity). Then by passing this energy through a low-pass filter and comparing the value with some per-defined threshold, we can detect spawning which is a typical approach used for fault detection [13]. We have chosen the energy signal as the marker because it is easier to obtain a pattern from the square of a velocity signal (having higher amplitude during spawning) than the velocity itself because of the amplitude. However, first we would like to process the raw data to reduce the computational burden. The idea is described in section V-A. The details of the spawning detection algorithm are given below.

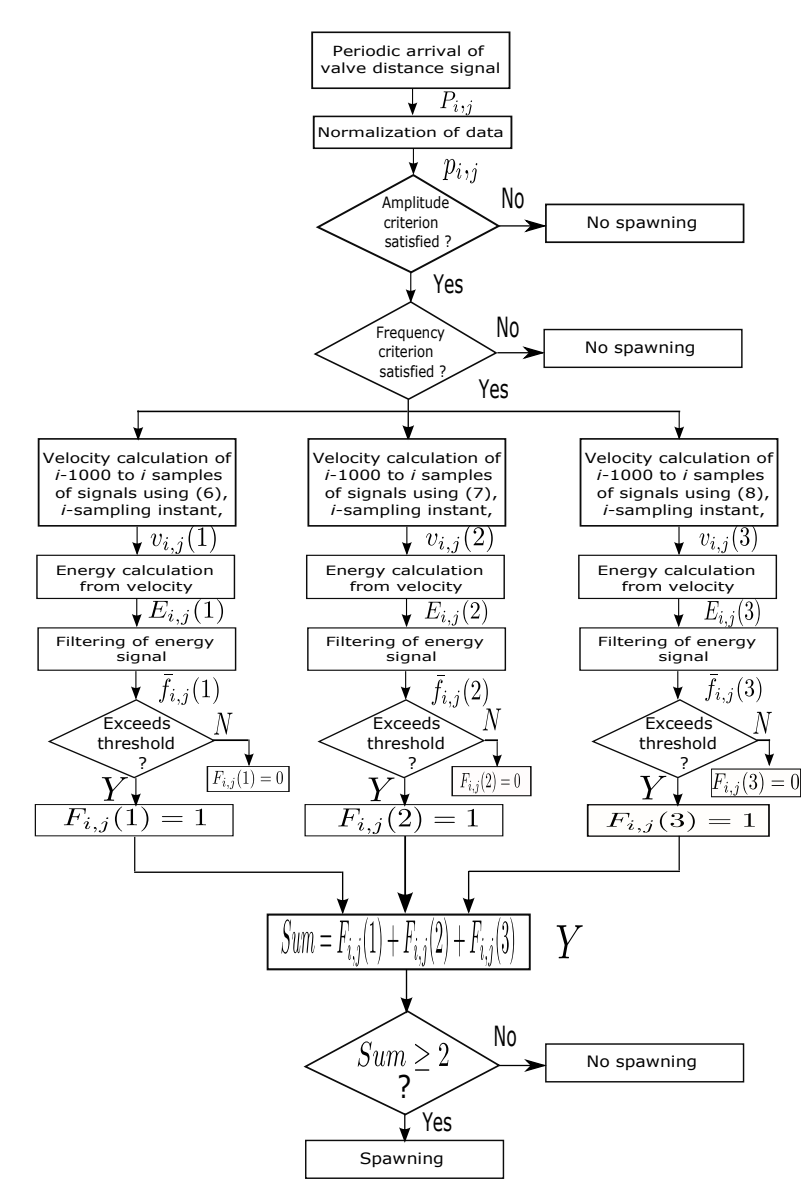

Figure 4. Flow chart of spawning detection process

\section{A. Rhythmicity Information Calculation}

During the spawning, the valve movement maintains a very periodic nature. A first step in identifying this pattern of behavior from others is to calculate the minimum and maximum of the signal amplitude for a certain interval (for example 1000 data points). This difference of the minimum and maximum value of the amplitude in this interval has a lower bound or threshold during spawning. If at current sampling instant, the difference of the minimum and maximum value of the amplitude in the interval of the signal exceeds the threshold, we will proceed further, otherwise we can say that spawning is not happening. Since the signal amplitude for different oysters varies widely just by using this criteria we may ignore a lot of potential spawning oysters. In the next step, we will calculate the frequency in this interval. If the frequency crosses a certain threshold, we will proceed to the rest of our algorithm which will use a velocity based detection of spawning. These two criteria will help us to eliminate a lot of data points which will in turn reduce the computational burden. The two criteria can be briefly described as:

- Amplitude criterion:

$$
\begin{aligned}
& A_{\text {int }}=\max \left(y_{i-1000, j}: y_{i, j}\right)-\min \left(y_{i-1000, j}: y_{i, j}\right), \\
& A_{\text {int }} \geq A_{\text {th }},
\end{aligned}
$$

where $i$ is the current sampling instant, $j$ is the oyster number, $A_{\mathrm{th}}$ is the amplitude threshold and the interval 
we are considering is from $i-1000$ to $i$, i.e. total 1001 datapoints.

- Frequency criterion:

$$
f_{\text {int }} \geq f_{\text {th }}
$$

where $f_{\text {int }}$ is the frequency of contraction of the interval and $f_{\text {th }}$ is the frequency threshold.

\section{B. Velocity Estimation}

Since velocity is the time derivative of valve distance activity, we need to differentiate the valve distance to get the velocity. A common technique is to use the Euler method that can be described as the difference between the current and previous sample divided by the sample time. However, this method does not work well in the presence of noise which is our case. However, there exist various effective methods to calculate the time derivative of noisy signals. For example, [24] proposed a numerical differentiation scheme based on an algebraic method. Homogeneous finite-time differentiation scheme can be found in [25] while non-homogeneous higher order sliding mode (HOSM) based differentiator was proposed in [26]. Out of various methods available, we have chosen the techniques proposed in the aforementioned references because of their simplicity, effectiveness and noise compensation [27]. In fault detection literature, hardware redundancy is a very well-known approach, where information from multiple hardware is passed through a voting scheme to detect the fault. We will use the same approach but from the software point of view which is known as analytical redundancy. We will use three different velocity estimation techniques and at the end the information obtained by different techniques will be passed through a voting scheme. This approach will help to minimize false detection and increase the rate of correct detection. The three differentiation schemes are summarized below:

1) Algebraic Differentiator: The algebraic time derivative estimation is based on the concepts of differential algebra and operational calculus. A more detailed description of the approach can be found in [24], [28] (see also [29], [30]). A moving horizon version of this technique is summarized below adapted from the mentioned references. For a realvalued signal $y(t)$, analytic on some time interval, the firstorder time derivative estimate can be written as:

$$
\widehat{\dot{y}}(t)=\frac{6}{T^{3}} \int_{0}^{T}(T-2 \tau) y(t-\tau) d \tau .
$$

The effect of the time integral, presented in equation (2), is obviously to dampen the impact of the measurement noise on the estimate. This noise dampening effect can also be used to filter out the noise from the original signal $y(t)$.

2) A non-homogeneous HOSM differentiator: Let us consider an unknown signal $y(t)$. To calculate the derivative of this signal, consider an auxiliary equation $\dot{x}=u$ where $x(t)$ denotes the estimate of the original signal $y(t)$. The control law $u$ is designed to drive the estimation error, i.e. $e(t)=x(t)-y(t)$, to zero. The work [26] proposes a variant of a super-twisting finite-time control $u$ that ensures vanishing the error $e(t)$ and its derivative $\dot{e}(t)$. Thus it can be used to provide a derivative estimate. It has also been shown that the obtained estimate is robust against a non-differentiable noise of any amplitude. Now if we consider a noisy version of the original signal, i.e. $\tilde{y}(t)=y(t)+\nu(t)$, where $\nu(t)$ is a bounded measurement noise, then the differentiator is given by [26]:

$$
\begin{aligned}
& \dot{x}_{1}=-\alpha \sqrt{\left|x_{1}-\tilde{y}(t)\right|} \operatorname{sign}\left(x_{1}-\tilde{y}(t)\right)+x_{2}, \\
& \dot{x}_{2}=-\beta \operatorname{sign}\left(x_{1}-\tilde{y}(t)\right)-\chi \operatorname{sign}\left(x_{2}\right)-x_{2},
\end{aligned}
$$

where $x_{1}, x_{2} \in \mathbb{R}$ are the state variables of the system (3), $\alpha, \beta$ and $\chi$ are the tuning parameters with $\alpha>0$ and $\beta>$ $\chi \geq 0$. The variable $x_{1}(t)$ serves as an estimate of the function $y(t)$ and $x_{2}(t)$ converges to $\dot{y}(t)$, i.e. it provides the derivative estimate. Therefore the system (3) has $\tilde{y}(t)$ as the input and $x_{2}(t)$ as the output.

3) Homogeneous finite-time differentiator: Consider a chain of integrators,

$$
\begin{aligned}
\dot{z}_{i} & =z_{i+1}, \text { for } i=1, \ldots, n-1, \\
\dot{z}_{n} & =u, \\
y & =z_{1},
\end{aligned}
$$

where $z \in \mathbb{R}^{n}$ is the state, $y \in \mathbb{R}$ is the output and $u \in \mathbb{R}$ is the input.

For the system (4), the following homogeneous finite-time differentiator can be proposed :

$$
\begin{aligned}
\dot{x}_{1} & =x_{2}-k_{1}\left\lfloor x_{1}-y\right\rceil^{\alpha}, \\
\dot{x}_{i} & =x_{i+1}-k\left\lfloor x_{1}-y\right\rceil^{i \alpha-(i-1)}, \text { for } i=2, \ldots, n-1, \\
\dot{x}_{n} & =-k_{n}\left\lfloor x_{1}-y\right\rceil^{n \alpha-(n-1)}+u .
\end{aligned}
$$

For details, [25] can be consulted.

\section{Filtering of energy signal and spawning detection}

From the normalized valve distance data $p_{i, j}$, using equations (2), (3) and (5), we can easily estimate the velocity $v_{i, j}(k)$, where $k=1,2,3$ represents algebraic differentiator, non-homogeneous HOSM differentiator and homogeneous finite-time differentiator respectively. Analytic expressions for three different cases are given below:

- Using algebraic differentiator (Section V-B1):

$$
v_{i, j}(1)=\frac{6}{M^{2} T_{s}} \sum_{l=0}^{M}\left(1-2 \frac{l}{M}\right) p_{i-l, j}
$$

- Using non-homogeneous HOSM differentiator (Sec. V-B2) and applying Euler discretization, the equation (3) can be written as

$$
\begin{aligned}
x_{1}(i, j)= & x_{1}(i-1, j)+T_{s}\{-\alpha \\
& \sqrt{\left|x_{1}(i-1, j)-\tilde{y}(i-1, j)\right|} \operatorname{sign}\left(x_{1}(i-1, j)\right. \\
& \left.-\tilde{y}(i-1, j))+x_{2}(i-1, j)\right\} \\
x_{2}(i, j)= & x_{1}(i-1, j)+T_{s}\left\{-\beta \operatorname{sign}\left(x_{1}(i-1, j)-\right.\right. \\
& \tilde{y}(i-1, j))-\chi \operatorname{sign}\left(x_{2}(i-1, j)\right) \\
& \left.-x_{2}(i-1, j)\right\}
\end{aligned}
$$

where $x_{1}(i, j)$ is the estimate of $p_{i, j}$ and $x_{2}(i, j)$ is the estimated velocity $v_{i, j}(2)$. 
- Using homogeneous finite-time differentiator (Section V-B3) and applying Euler discretization, the equation (5) for calculating first order derivative can be written as

$$
\begin{aligned}
& x_{1}(i, j)=x_{1}(i-1, j)+ \\
& T_{s}\left(x_{2}(i, j)-k_{1}\left\lceil x_{1}(i-1, j)-y(i-1, j)\right\rfloor^{\alpha}\right),
\end{aligned}
$$

$$
\begin{aligned}
& x_{2}(i, j)=x_{2}(i-1, j)+ \\
& T_{s}\left(-k_{2}\left\lceil x_{1}(i-1, j)-y(i-1, j)\right\rfloor^{2 \alpha-1}\right),
\end{aligned}
$$

where $x_{1}(i, j)$ is the estimate of $p_{i, j}$ and $x_{2}(i, j)$ is the estimated velocity $v_{i, j}(3)$.

Notice that equations (6), (7) and (8) are in discrete form since in our case only discrete measurements are available.

From the estimated velocity, the kinetic energy like signal can be calculated just by taking square of the velocity signal $v_{i, j}(k)$ :

$$
E_{i, j}(k)=v_{i, j}^{2}(k),
$$

where $E_{i, j}(k)$ is the energy. This signal will be passed through the following low-pass like filter:

$$
f_{i+1, j}(k)=f_{i, j}(k)+T_{s}\left(\min \left(\gamma,\left|E_{i, j}(k)\right|\right)-\mu f_{i, j}(k)\right)
$$

where $f_{i, j}(k)$ is the filtered signal, Ts $=1.6 \mathrm{sec}$. is the sampling period and $\mu$ and $\gamma$ are the parameters of the filters. The filtered signal obtained through (9) will then be passed through another typical low-pass filter to eliminate the remaining high frequency fluctuation of the energy signal. A typical discrete first order low pass filter has the following form:

$$
\bar{f}_{i, j}=\alpha \bar{f}_{i-1, j}+(1-\alpha) f_{i, j}
$$

where $\bar{f}_{i, j}$ is the filtered signal, $f_{i, j}$ is the original signal, $\alpha=\frac{\tau_{f}}{\tau_{f}+T_{s}}, \tau_{f}$ is the time constant of the filter and $T_{s}$ is the sampling time. This doubly filtered energy signal $\bar{f}_{i, j}(k)$ will then be used for the detection of the spawning. If the signal exceeds some threshold, it will be considered as spawning, otherwise no spawning:

$$
\mathrm{F}_{i, j}(k)= \begin{cases}1, & \bar{f}_{i, j}(k) \geq \beta \\ 0, & \text { otherwise }\end{cases}
$$

where $\beta$ is the threshold for spawning.

\section{Decision rule}

The last step is to come to a final decision about spawning from the 3 different flags obtained through eq. (11). Since no prior information is available about the performance of individual detection scheme, no weight was associated with each flag of the eq. (11). There are two popular choices for unweighted voting (i.e. unanimity and majority), and here a majority based voting technique was used to determine whether spawning is happening at the current sampling instant or not. If at least two flags of eq. (11) have value 1 then it is spawning, otherwise not. The expression is given below:

$$
\text { Spawning }_{i, j}= \begin{cases}1, & \sum_{k=1}^{3} \mathrm{~F}_{i, j}(k) \geq 2 \\ 0, & \text { otherwise }\end{cases}
$$

The flow chart of the whole process can be seen in Fig. 4. The parameters of the algorithm were tuned on a trial and error basis since establishing some tuning rule is very difficult because of the wide variations of behavior among different animals. The values of the parameters are omitted for space limitations. In our current work, we have done the detection offline, however, the algorithm is designed for online detection and it is planned for the future.

\section{Results And Discussions}

As mentioned in Section IV, by visual inspection of the dataset, the spawning oysters can be identified. After such an expert evaluation, for dataset 1 , the oysters $1,3,4,10$, $11,12,13$ and 16 were classified as clearly visible spawning oysters with spawning period of about $30-40$ minutes and having very regular rhythmic contraction and relaxation of valves. So, the algorithm is supposed to find these spawning oysters. Next, the proposed algorithm has been applied. For example, the data of oysters 1 and 5 can be seen in Fig. 5 . According to the criteria mentioned in Section IV, oyster 1 is classified as a typical spawner while 5 appears to exhibit a much lesser typical burst of contraction. Note that to know if 5 was really spawning or not would require the ability to check if it produces eggs or not which was out of the scope of the present work. The final output of our algorithm for dataset 1 can be seen in Fig. 6. Horizontal axis of all the figures in this Section are in hour format.

For dataset 2, we have first applied our algorithm to find spawning oysters and then we have asked expert evaluation to validate the effectiveness of our algorithm. We found that the oysters 1, 4, 5, 6 and 7 were spawning on September 6, 2013 between $8-10$ a.m. All the spawning oysters were diploid. No triploid oysters showed clearly distinguishable spawning behavior. Expert evaluation confirmed our result. It is to be noted here that for dataset 2, spawning happened almost 2 months later than for dataset 1 . Detection result for dataset 2 can be seen in Fig. 7.

In dataset 3, we have found that spawning happened two times unlike one time in dataset 1 and 2 . The first time, spawning happened on the 15th of July, 2014 which is the same date as in dataset 1 while second spawning happened on the 11th of August. So, there is a gap of almost 1 month. Like dataset 2 , in this case also only diploid oysters showed clearly distinguishable spawning behavior and not the triploids. In July 15 , the oysters $2,3,5,6$ and 8 were spawning while in August 11, the oysters 1, 2, 6 and 8 were spawning. Detection results for July 15 case can be seen in Fig. 8 and in Fig. 9 for August 11.

From figures 6, 7, 8 and 9, it is clear that our algorithm can successfully detect the start and end of spawning. We can also see that our algorithm can detect the spawning for all the clear cut spawning oysters. There is no false alarm and zero misdetection. This proves the effectiveness of our algorithm. However, in some cases we can see a little delayed detection. This delay comes from the filtering and differentiation process and it is very common.

As mentioned in Section IV, according to [12], spawning propagates from one to another and then induces an increased 

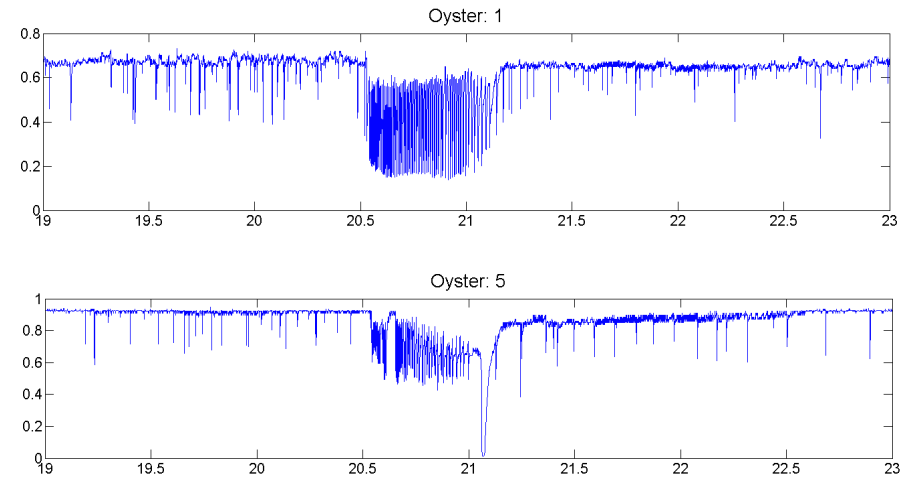

Figure 5. Valve activity of oyster 1 and 5 (x-axis is in hour and y-axis is normalized valve distance)

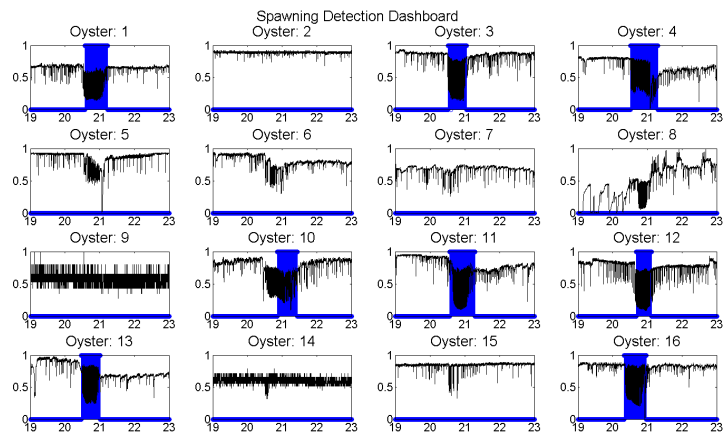

Figure 6. Spawning detection for the population of dataset 1 (2007)

burst activity that eventually spread to most individuals. This is a very important criteria to check if the oysters are really spawning, which may tolerate the effect of wrong detection from the algorithm for certain oysters. If they are really spawning, we would see the spawning propagating, otherwise not. One way to check this criteria is to calculate the number of oysters simultaneously spawning at a given time. The number of simultaneously spawning oysters in dataset 1 can be seen in Fig. 10 where we can notice that the spawning spread from one oyster to another and then eventually spread to the entire community. At the peak of spawning, all female oysters were spawning. This is a very strong proof of spawning and also tells the effectiveness of the spawning detection algorithm. Moreover, we can see that it took very short time to propagate spawning from the first spawning oyster to the second one and much less for the rest of the oysters.

The number of simultaneously spawning oysters in dataset 2 can be seen in Fig. 11. In both cases (1 and 2), we have seen simultaneous spawning that confirmed the effectiveness of our detection algorithm. The number of simultaneously spawning oysters in dataset 3 is omitted due to space limitation.

The proposed algorithm was compared with a FFT (Fast Fourier Transformation) based technique. A lot of false detection were observed in the FFT based case. Unlike rotating machineries, the fault frequencies are different for different oysters which leads to significant false detection. The result of the comparison is omitted due to space limitations.
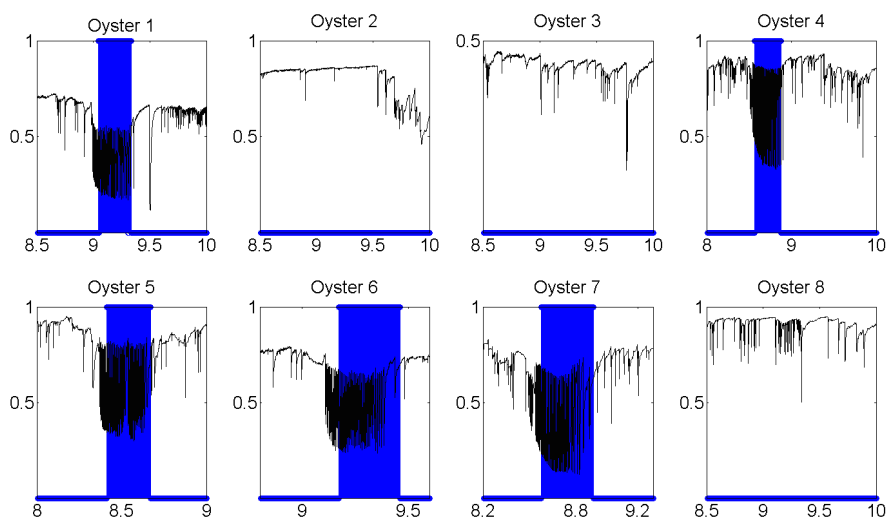

Figure 7. Spawning detection result for dataset 2
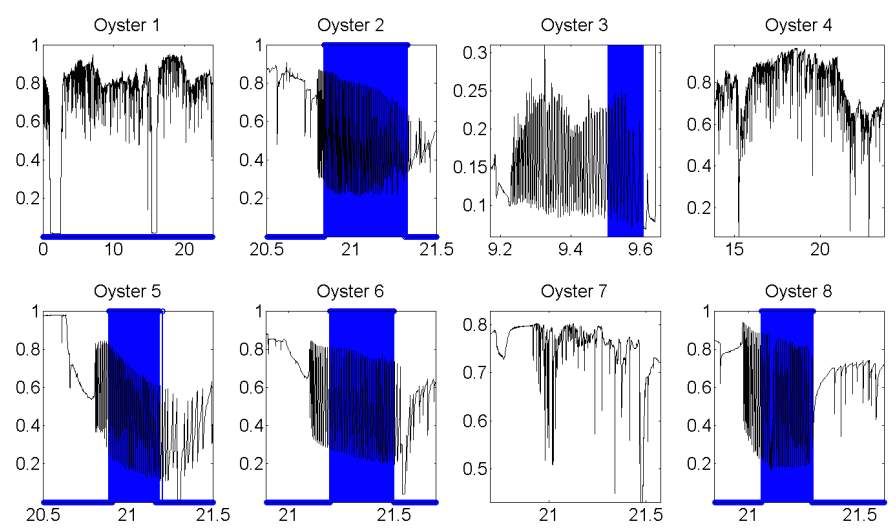

Figure 8. Spawning detection result for July 15 case (dataset 3)
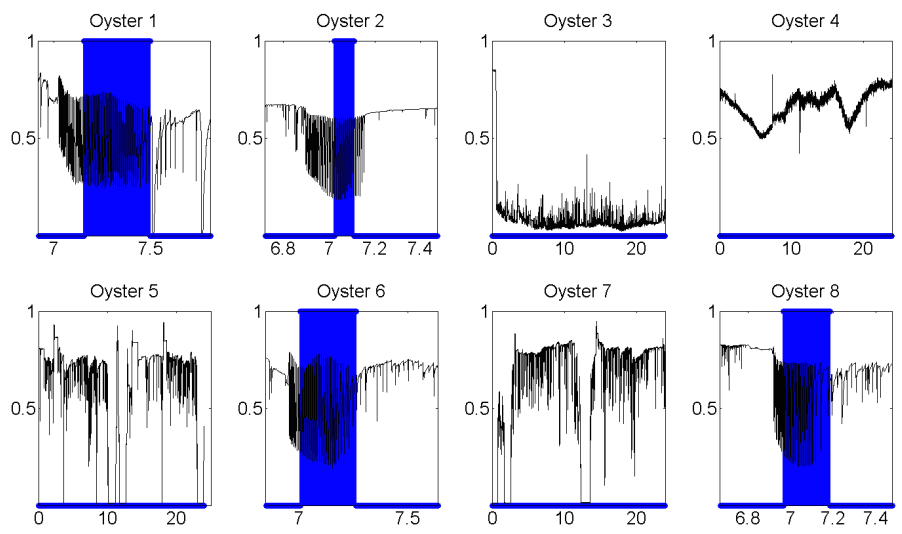

Figure 9. Spawning detection result for August 11 case (dataset 3)

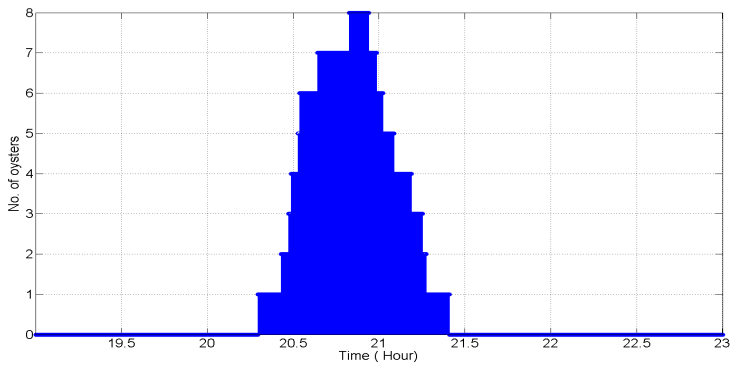

Figure 10. Number of simultaneously spawning oysters 


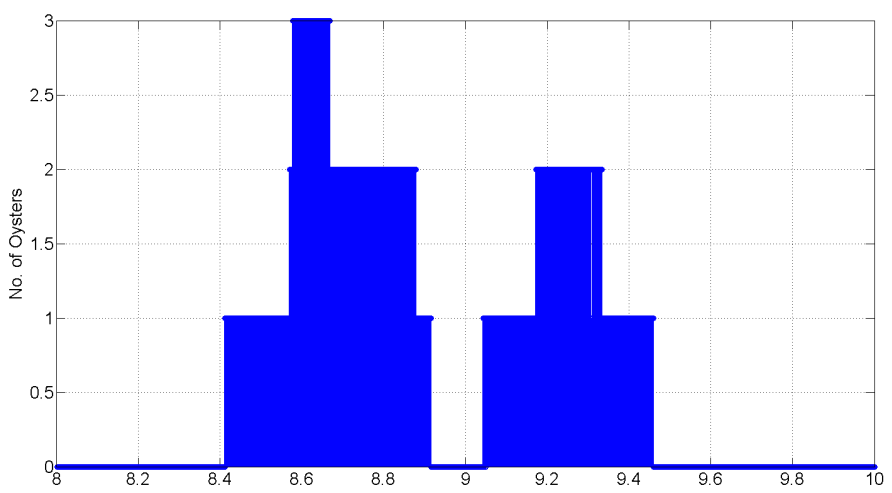

Figure 11. Number of simultaneously spawning oysters in dataset 2

\section{CONCLUSIONS}

This paper presents an algorithm to automatically detect the start and end of the spawning period of a population of oysters that is to detect individual spawning events and the day of spawning. The developed algorithm is based on the estimation of velocity of valve movement. The algorithm was then tested on three different populations to approve its effectiveness. The obtained results are very promising and open up the scope of real-time spawning detection of oyster population in marine environment.

In future works, the algorithm can be tested on new measurement sites and different bivalves species. Very noisy/faulty measurement detection system can also be included into the algorithm to prevent any false/early/late detection. Once a spawning day has been automatically identified, it is a solid working base for an expert to screen the records and classify the atypical bursts of contractions. Different parameters of the algorithm were chosen on a trial and error basis. In future, establishing a numerical procedure for the tuning of the parameters will also be considered.

\section{REFERENCES}

[1] E. D. Goldberg, "The mussel watch-a first step in global marine monitoring," Marine Pollution Bulletin, vol. 6, no. 7, p. 111, 1975.

[2] A. Tanguy, I. Boutet, R. Riso, P. Boudry, M. Auffret, and D. Moraga, "Metallothionein genes in the european flat oyster ostrea edulis: a potential ecological tool for environmental monitoring?," Marine ecology. Progress series, vol. 257, pp. 87-97, 2003.

[3] P. Scanes, "Oyster watch: Monitoring trace metal and organochlorine concentrations in sydney's coastal waters," Marine Pollution Bulletin, vol. 33, no. 7, pp. 226-238, 1996.

[4] A. M. Mat, J.-C. Massabuau, P. Ciret, and D. Tran, "Evidence for a plastic dual circadian rhythm in the oyster crassostrea gigas," Chronobiology international, vol. 29, no. 7, pp. 857-867, 2012.

[5] A. M. Mat, J.-C. Massabuau, P. Ciret, and D. Tran, "Looking for the clock mechanism responsible for circatidal behavior in the oyster crassostrea gigas," Marine Biology, vol. 161, no. 1, pp. 89-99, 2014.

[6] D. Tran, A. Nadau, G. Durrieu, P. Ciret, J.-P. Parisot, and J.-C. Massabuau, "Field chronobiology of a molluscan bivalve: How the moon and sun cycles interact to drive oyster activity rhythms," Chronobiology international, vol. 28, no. 4, pp. 307-317, 2011.

[7] C. Schwartzmann, G. Durrieu, M. Sow, P. Ciret, C. E. Lazareth, and J.-C. Massabuau, "In situ giant clam growth rate behavior in relation to temperature: A one-year coupled study of high-frequency noninvasive valvometry and sclerochronology," Limnology and oceanography, vol. 56, no. 5, pp. 1940-1951, 2011.

[8] D. Tran, H. Haberkorn, P. Soudant, P. Ciret, and J.-C. Massabuau, "Behavioral responses of crassostrea gigas exposed to the harmful algae alexandrium minutum," Aquaculture, vol. 298, no. 3, pp. 338-345, 2010.
[9] A. M. Mat, H. Haberkorn, J.-P. Bourdineaud, J.-C. Massabuau, and D. Tran, "Genetic and genotoxic impacts in the oyster crassostrea gigas exposed to the harmful alga alexandrium minutum," Aquatic Toxicology, vol. 140, pp. 458-465, 2013.

[10] D. Tran, J.-C. Massabuau, and C. Vercelli, "Influence of sex and spawning status on oxygen consumption and blood oxygenation status in oysters crassostrea gigas cultured in a mediterranean lagoon (thau, france)," Aquaculture, vol. 277, no. 1, pp. 58-65, 2008.

[11] H. Ahmed, R. Ushirobira, D. Efimov, D. Tran, J.-C. Massabuau, et al. "Dynamical model identification of population of oysters for water quality monitoring," in Proc. European Control Conference (ECC) 2014, 2014.

[12] P. S. Galtsoff, "Physiology of reproduction of ostrea virginica i. spawning reactions of the female and male," The Biological Bulletin, vol. 74, no. 3, pp. 461-486, 1938.

[13] A. Zolghadri, D. Henry, J. Cieslak, D. Efimov, and P. Goupil, Fault Diagnosis and Fault-Tolerant Control and Guidance for Aerospace Vehicles. Springer, 2014.

[14] M. Blanke and J. Schröder, Diagnosis and fault-tolerant control, vol. 2. Springer, 2006.

[15] R. Isermann, Fault-diagnosis systems. Springer, 2006.

[16] M. Sow, G. Durrieu, L. Briollais, P. Ciret, and J.-C. Massabuau, "Water quality assessment by means of hfni valvometry and high-frequency data modeling," Environmental monitoring and assessment, vol. 182, no. 1-4, pp. 155-170, 2011.

[17] F. G. Schmitt, M. De Rosa, G. Durrieu, M. Sow, P. Ciret, D. Tran, and J.C. Massabuau, "Statistical study of bivalve high frequency microclosing behavior: Scaling properties and shot noise analysis," International Journal of Bifurcation and Chaos, vol. 21, no. 12, pp. 3565-3576, 2011.

[18] D. Tran, P. Ciret, A. Ciutat, G. Durrieu, and J.-C. Massabuau, "Estimation of potential and limits of bivalve closure response to detect contaminants: application to cadmium," Environmental Toxicology and Chemistry, vol. 22, no. 4, pp. 914-920, 2003.

[19] C. Chambon, A. Legeay, G. Durrieu, P. Gonzalez, P. Ciret, and J. Massabuau, "Influence of the parasite worm polydora sp. on the behaviour of the oyster crassostrea gigas: A study of the respiratory impact and associated oxidative stress," Mar. Biol., vol. 152, pp. 329-338, 2007.

[20] H. Ahmed, R. Ushirobira, D. Efimov, D. Tran, M. Sow, and J.-C. Massabuau, "Automatic spawning detection in oysters: a fault detection approach (to appear)," in Proc. European Control Conference (ECC) $2015,2015$.

[21] E. His, Contribution à l'étude biologique de l'huitre dans le bassin d'Arcachon. Activité valvaire de Crassostrea angulata et de Crasssotrea gigas ; application à la reproduction de l'huitre japonaise. $\mathrm{PhD}$ thesis, University of Bordeaux 1, 1976.

[22] I. Bernard, Ecologie de la reproduction de l'huitre creuse, Crassostrea gigas, sur les cotes atlantiques francaises: vers une explication de la variabilite du captage. PhD thesis, University of La Rochelle, 2011.

[23] S. K. Allen, P. M. Gaffney, and J. W. Ewart, Genetic improvement of the eastern oyster for growth and disease resistance in the Northeast. Northeastern Regional Aquaculture Center, University of Massachusetts, Dartmouth, 1993.

[24] M. Mboup, C. Join, and M. Fliess, "Numerical differentiation with annihilators in noisy environment," Numerical Algorithms, vol. 50, no. 4, pp. 439-467, 2009.

[25] W. Perruquetti, T. Floquet, and E. Moulay, "Finite-time observers: application to secure communication," Automatic Control, IEEE Transactions on, vol. 53, no. 1, pp. 356-360, 2008.

[26] D. Efimov and L. Fridman, "A hybrid robust non-homogeneous finitetime differentiator," Automatic Control, IEEE Transactions on, vol. 56, no. 5, pp. 1213-1219, 2011.

[27] H. Ahmed, R. Ushirobira, D. Efimov, D. Tran, and J.-C. Massabuau, "Velocity estimation of valve movement in oysters for water quality surveillance (to appear)," in Modelling, Identification and Control of Nonlinear Systems (MICNON), 2015 IFAC Conference on, 2015.

[28] R. Ushirobira, W. Perruquetti, M. Mboup, and M. Fliess, "Algebraic parameter estimation of a multi-sinusoidal waveform signal from noisy data," in Control Conference (ECC), 2013 European, pp. 1902-1907, IEEE, 2013.

[29] J. Reger and J. Jouffroy, "On algebraic time-derivative estimation and deadbeat state reconstruction," in Decision and Control, 2009 held jointly with the 2009 28th Chinese Control Conference. CDC/CCC 2009. Proceedings of the 48th IEEE Conference on, pp. 1740-1745, Dec 2009.

[30] J. Reger and J. Jouffroy, "Prooving identities with computer-algebra example: Algebraic time-derivative estimation," PAMM, vol. 8, no. 1, pp. 10905-10906, 2008. 